\title{
Study of potential wind power as a renewable energy source in the Motru area
}

\author{
Alin Sultan, Marin Silviu Nan, Cristian Ilioni, Cosmin Vitan", and Nicoleta Mamara \\ University of Petrosani, 20 University street, 332006, Petrosani, Romania
}

\begin{abstract}
The continuous development of the human society is in a close correlation with the increased consumption of electricity. In the past few years, the thirst for electricity at a global level, has led both to higher levels of pollution and the depletion of fossil fuels. For this reason, the issue of energy efficiency is a priority of energy strategy at national and EU level. In this context, a solution to the above problems is to increase the rate of production of electricity from renewable energy sources. Thus, the paper presents a study of wind energy as a source of renewable energy, their modelling and simulation for the Motru area.
\end{abstract}

\section{Introduction}

Renewable energy sources are highly appreciated at this moment and their effectiveness has been recognized worldwide. For promoting renewable energy sources, many states have developed and implemented policies and strategies that facilitate access to these sources in the electricity system and support investments in this area [1].

Renewable energy refers to forms of energy produced by the energy transfer of energy resulting from renewable natural processes. Thus, the energy of sunlight, winds, flowing water, biological processes and geothermal heat can be captured using various methods. Renewable energy sources include: solar energy, wind energy, energy derived from biomass; water energy and geothermal energy [2].

Renewable energies, where the source of production is water, wind and solar radiation are an alternative to fossil fuel energy for several reasons: they are inexhaustible, have a minimal effect on the environment, do not emit greenhouse gases and do not produce waste, allow a decentralized production of energy adopted to local needs and resources and offers important energy independence [3].

Renewable energies are an alternative to fossil fuel energy for several reasons: they are inexhaustible, they have a minimal effect on the environment, they do not emit greenhouse gases and do not produce waste, and they allow a decentralized production of energy adapted to local needs and resources and provide important energy independence.

Wind power has a number of benefits that detach it from other renewable energy sources. First of all, the primary source of energy, the wind, is available in abundance

\footnotetext{
* Corresponding author: vitan.daniel.cosmin@gmail.com
} 
globally both on land and on water. Secondly, the costs of investments for wind energy are low compared to the production of energy using photovoltaic panels [3], [4].

According to documents prepared by the European Union (EU), the integration of renewable energy sources into the electricity market is constantly increasing and it is expected that by 2030 it will become an important source of electricity [5]. It is expected that by 2050 renewable energy sources will cover a large part of electricity consumption, Figure 1, which would lead to a reduction of $\mathrm{CO}_{2}$ emissions generated by the burning of fossil fuels and to a reduction of the European Union's dependence on fossil fuel imports.

Energy consumption in the EU increased by 1\% in 2017 compared to 2016 thus continued to expand energy efficiency target and setting a new target for the electricity consumption from primary sources of energy for 2020 or 2030, Figure 1 . The energy production on primary energy sources for 2018 is shown in Figure 2, where the energy produced by the wind has a share of $11.7 \%$ of the total energy for the EU, respectively $12.7 \%$ in Romania [5].

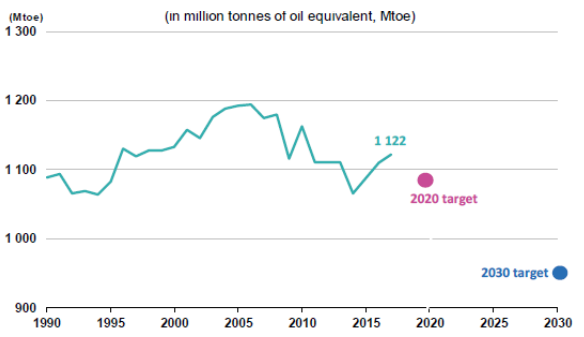

Fig. 1. Energy consumption in the EU, 2017 and target for 2020 and 2030.

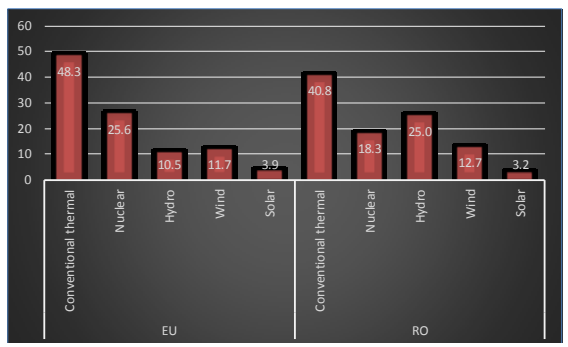

Fig. 2. Electricity production by source, 2018 (in \%) EU and Romania.

\section{Mathematical model of wind turbine}

The complete model of a wind energy conversion system is constructed from a number of components. Figure 3 presents the block diagram of a wind energy conversion system.

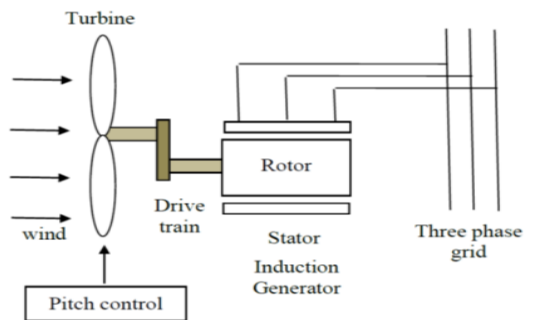

Fig. 3. The block diagram of a wind energy conversion system. 
The energy produced by the wind turbine depends on the interaction between the wind and the turbine rotor. Turbine blades are designed to capture wind energy and transfer it to turbine rotor [6].

The mathematical model of the wind turbine is based on two mathematical relations:

- The relation between wind speed and aerodynamic power, given by the following relation:

$$
P_{m}=\frac{\rho \cdot A}{2} \cdot v_{\text {wind }}^{3} \cdot C_{p}(\lambda, \beta)
$$

where $\rho\left[\mathrm{kg} / \mathrm{m}^{3}\right]$ is the air density; $P_{m}[\mathrm{~W}]$ is mechanical output power of the turbine; $\lambda=\frac{\omega_{r} \cdot R}{v_{\text {wind }}} ; \omega_{r}=\frac{2 \cdot \pi \cdot n}{60}$ is tip speed ratio of the rotor blade tip speed to wind speed; $v_{\text {wind }}$ $[\mathrm{m} / \mathrm{s}]$ is wind speed; $\beta$ [degree] is blade pitch angle air density; $A\left[\mathrm{~m}^{2}\right]$ is the turbine swept area $\left(A=\pi \cdot R^{2}, R\right.$ is the rotor radius); $n$ [rot $\left./ \mathrm{min}\right]$ is the rotor speed of generator; $C_{p}$ is performance coefficient of the turbine, relation (2).

$$
C_{p}(\lambda, \beta)=c_{1}\left(\frac{c_{2}}{\lambda_{i}}-c_{3} \beta-c_{4}\right) e^{\frac{-c_{5}}{\lambda_{i}}}+c_{6} \lambda
$$

where: $\frac{1}{\lambda_{i}}=\frac{1}{\lambda+0.08 \beta}-\frac{0.035}{\beta^{3}+1}$

- The relationship defining the aerodynamic torque:

$$
T_{m}=\frac{P_{m}}{\omega_{r}}
$$

where $\omega_{r}[\mathrm{rad} / \mathrm{sec}]$ is angular speed of the generator rotor; $T_{m}[N \cdot \mathrm{m}]$ is the aerodynamic torque.

The coefficients $\mathrm{c}_{1}$ to $\mathrm{c}_{6}$ are: $\mathrm{c}_{1}=0.5176, \mathrm{c}_{2}=116, \mathrm{c}_{3}=0.4, \mathrm{c}_{4}=5, \mathrm{c}_{5}=21$ and $\mathrm{c}_{6}=$ 0.0068. Characteristic of wind turbine, $C_{p}(\lambda, \beta)$, for different values of the pitch angle $\beta$, are illustrated in Figure 4. The maximum value of $C_{p}\left(\mathrm{c}_{\mathrm{pmax}}=0.48\right)$ is achieved for $\beta=0$ degrees and for $\lambda=8.1$. This particular value of $\lambda$ is defined as the nominal value ( $\lambda \_$nom).

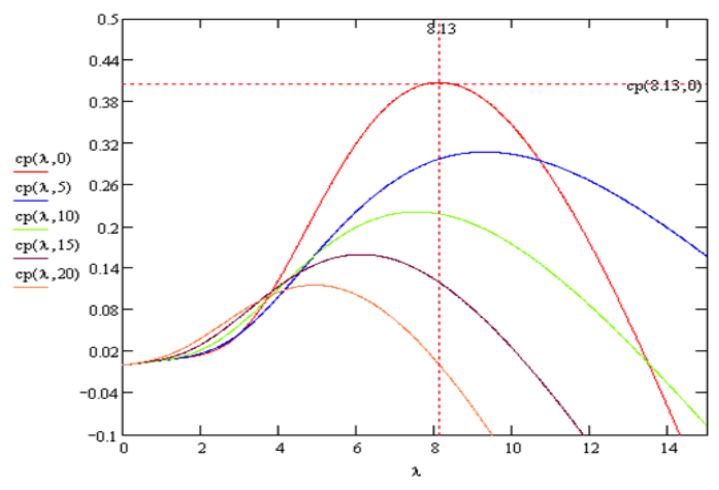

Fig. 4. Characteristic of wind turbine. 
Based on the above mentioned simulation model in Matlab - Simulink [7] of the wind turbine is presented in Figure 5 and taking into account that the air density $\rho=1.2\left[\mathrm{~kg} / \mathrm{m}^{3}\right]$, the variation of the mechanical power with respect to the rotor speed, for various values of wind speed, is shown in Figure 6.

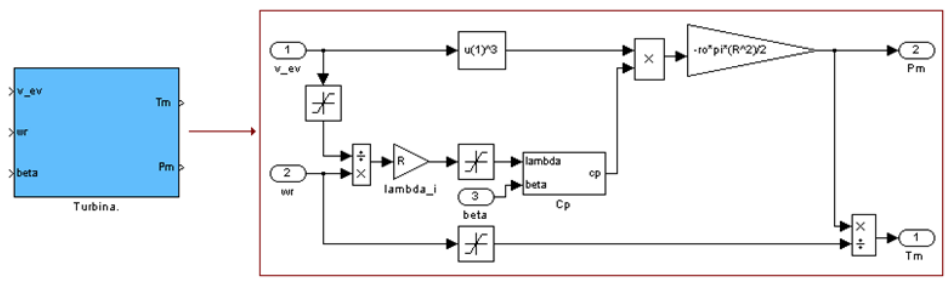

Fig. 5. Matlab-Simulink model of the turbine.

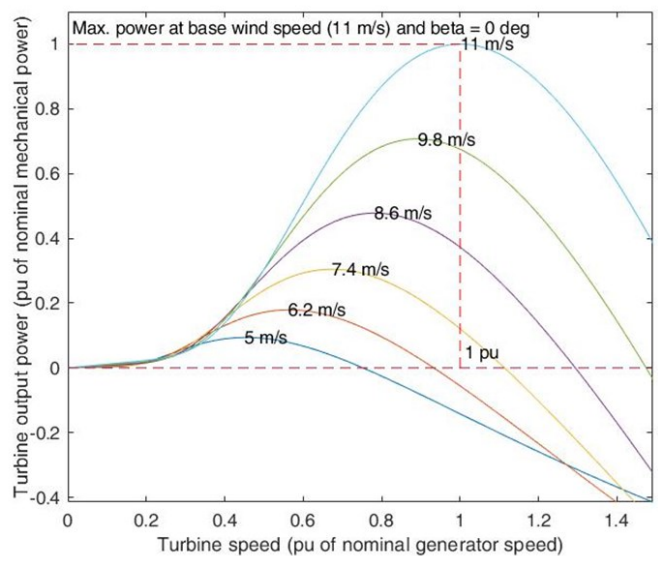

Fig. 6. Turbine output power characteristic.

\section{Simulation of the wind energy production system for the Motru area}

In the following lines we will customize the shown above mathematical models, for Motru area.

Motru municipality is located in the southwest part of the County of Gorj from Romania, at the dividing line between the Mehedinti and Gorj County. The municipality is located on route DN 67A, at $44 \mathrm{~km}$ from Targu-Jiu and at $42 \mathrm{~km}$ from Drobeta Turnu Severin. The coordinates of the city are: latitude [degrees] is 44.80 and longitude [degree] is 22.98 [8].

The meteorological system used, belonging to the University of Petrosani [9] is intended for continuous monitoring of the meteorological parameters in the industrial areas that are sources of pollution in the areas where the wind farms will be located. The weather station, Figure 7, acquires information about the following variables: ambient temperature, solar radiation intensity, humidity, barometric pressure, altitude, wind speed, wind direction and precipitation. 


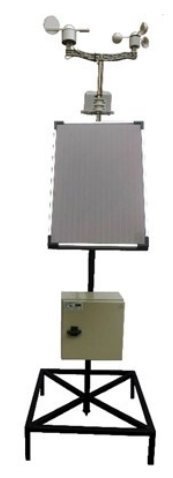

Fig. 7. The meteorological stations.

Following the analysis of the data collected from the Motru area, regarding the wind speed during 2018, it was observed that the average speed was about $4 \mathrm{~m} / \mathrm{s}$, in the south direction, Figure 8. The maximum wind speed, during 2018, was $18 \mathrm{~m} / \mathrm{s}$, being measured at the beginning of February.
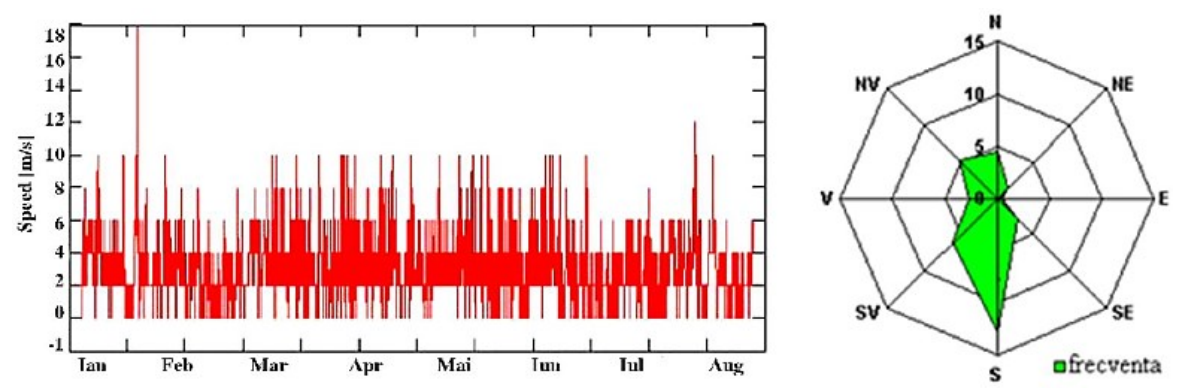

Fig. 8. Variation of wind speed during 2018 and frequency of wind beat.

The wind speed increases with the increase of the height towards the ground. A good approximation is achieved by using the following logarithmic relation:

$$
v=v_{\text {ref }} \cdot\left(\frac{h}{h_{\text {ref }}}\right)^{\alpha}
$$

where: $v_{r e f}[\mathrm{~m} / \mathrm{s}]$ is known/ measured wind speed at the reference level $h_{r e f}[\mathrm{~m}] ; v[\mathrm{~m} / \mathrm{s}]$ is wind speed at height, $h[\mathrm{~m}]$, of the wind turbine rotor; $\alpha$ is:

$$
\alpha=\frac{0.37-0.088 \cdot \ln \left(v_{r e f}\right)}{1-0.088 \cdot \ln \left(\frac{h_{r e f}}{10}\right)}
$$

The evaluation of the transient stability of the wind turbine, implemented with induction generators (study system), at the measured wind speed, often determines the fluctuations of power in an active wind turbine. In this example, Figure 9, a $13.5 \mathrm{MW}$ wind farm is simulated with wind turbines with generators. Thus the wind farm consists of nine $1.5 \mathrm{MW}$ wind turbine and is connected to a power distribution system. The pitch angle is controlled to limit the output power of the generator to its nominal value for winds exceeding the rated speed $(15 \mathrm{~m} / \mathrm{s})$. Each wind turbine has a protection system monitor the voltage, current and machine speed. 


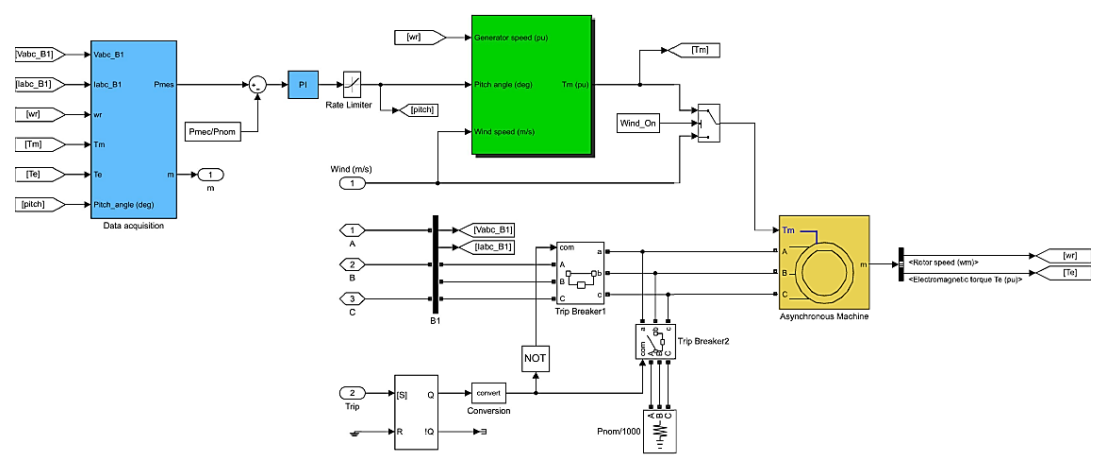

Fig. 9. MATLAB-Simulink model of the wind turbine.

The mechanical power of turbine depending on the speed of the turbine is displayed for wind speeds between $4 \mathrm{~m} / \mathrm{s}$ and $11 \mathrm{~m} / \mathrm{s}$. In this example, the system is observed for 20 seconds and the simulation data are: stator resistance $R_{s}=0.00483$ [pu]; stator leakage inductance $L_{s}=0.1248[\mathrm{pu}]$; magnetizing inductance $L_{m}=6.77[\mathrm{pu}]$; rotor resistance $R_{r}=$ 0.00437 [pu]; stator leakage inductance $L_{r}=0.1791[\mathrm{pu}]$; number of pole pairs $P=3$; combined generator and turbine inertia constant $H=5.04[\mathrm{~s}]$; combined viscous friction factor $F=0.01[\mathrm{pu}]$; mechanical output power of the turbine $P_{m}=1.5[\mathrm{~kW}]$; value of the wind speed $v_{\text {wind }}=11[\mathrm{~m} / \mathrm{s}]$; pitch angle $\max \beta_{\max }=45$ [degree]; max rate of change of pitch angle is 2 [degree/s]; proportional and integral gains $\mathrm{Kp}=5$ [degrees/(power deviation $\mathrm{pu})]$ and $\mathrm{Ki}=25$ [degrees/(power deviation $\mathrm{pu}) / \mathrm{s}$ ] of the pitch controller.

The result simulations, at the theoretical conditions, are presented in Figure 10. The output power changes with the variation of wind speed.
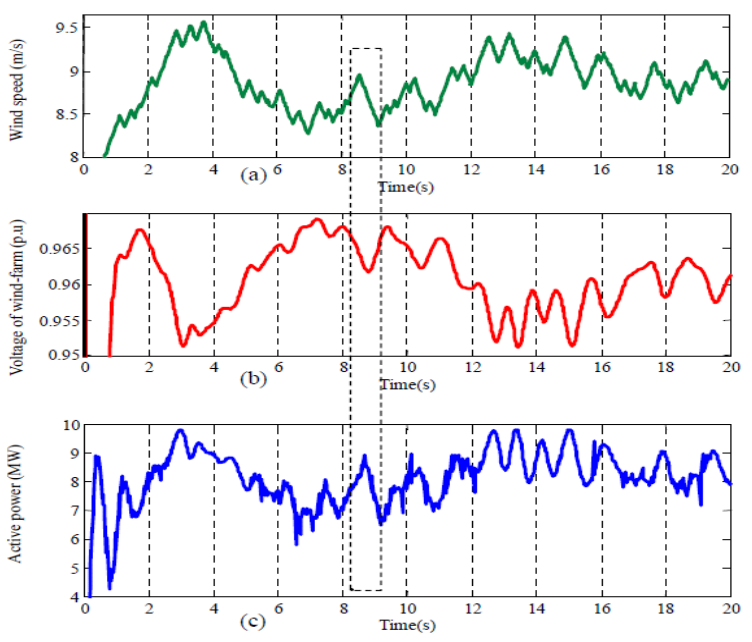

Fig. 10. The result of the simulation (a) Wind speed; (b) Output voltage of wind turbine; (c) Output power.

The exact analysis of Figure 10 shows that the output voltage will change in the opposite direction increases the wind speed, and as power increases, the voltage decreases. 
Variation of wind speed often causes an active wind turbine and power fluctuations, especially when the wind farm connects to a network, fluctuations occur with the variation of wind speed, Figure 10 presents this aspect.

According to equation (1), it is clear that the torque and power are square proportional to the wind speed.

From the above simulation result, it can be concluded that the maximum mechanical power obtained from the simulated wind turbine is at the maximum wind speed at $11 \mathrm{~m} / \mathrm{s}$ with a pitch angle $\beta=0$ and the value obtained for 9834.39 [W]. Results of simulation can be confirmed analytically by use equations (1) - (5).

\section{Conclusions}

The use of wind energy is becoming more attractive, the modelling and simulation of wind turbine systems allows the study of the parameters that lead to increased capacities of electricity generation. It can be concluded that in the design of the wind farm must take into account many factors but the most important are the area and the climatic conditions.

The MATLAB-Simulink model can be further used in optimization and increase produced wind energy.

Renewable energy based on wind conversion systems needs an adaptive mathematical algorithm and an efficient dynamic response control system to always be able to withstand the sudden change in wind speed.

Thus highly variable renewable sources, such as wind energy, depending on the wind speed variation, need predictive control solutions for the energy produced to be maxim and constant.

Over the last decade, the installation of wind turbine farms worldwide has spread rapidly. The present paper examined the current state of wind energy and presented the technologies related to this industry. Thus, the trend is embraced and supported for renewable energy installations through the use of advanced materials that could capture larger quantities of wind energy and with greater reliability, through the implementation of advanced control and monitoring systems.

It should be emphasized that the dominance of environmentally friendly energy sources, which are economically competitive over fossil fuel energy sources, is something that could benefit the whole of humanity in terms of sustainable energy security development.

\section{References}

1. A.K. Giri, S.R. Arya, R. Maurya, IEEE Transactions on Industrial Electronics, 66, (11), 90239031, (2018)

2. D.A. Ciupageanu, G. Lazaroiu, M. Tirsu, Proceedings of the 2017 IEEE International Conference on Electromechanical and Power Systems SIELMEN2017, 281-85, (2017)

3. D.A. Ciupageanu, G. Lazaroiu, L. Barelli, Proceedings of the 18th International Multidisciplinary Scientific Geoconference SGEM 2018 18, (4.1), 807-815 (2018)

4. A.H. Abobkr, M.E. El-Hawary, Proceedings of the 2016 IEEE Electrical Power and Energy Conference (EPEC), (2019)

5. European Commission-Energy. Available on: https://ec.europa.eu/energy/en

6. D.A. Ciupageanu, G. Lazaroiu, V. Berbece, M Tirsu, V. Galbura, 14th IEEE International Conference on Development and Application Systems DAS2018, 26-30, (2018)

7. MATLAB-Simulink software User Guide. Available on https://www.mathworks.com/products/simulink.html

8. M.S. Nan, A. Sultan, D. Grecea, C. Vitan, Proceedings of the 9th International Conference on Manufacturing Science and Education -MSE 2019- (2019)

9. N. Diaconu, M.S. Nan, O. Stoicuta, et al, Industria Textila, 70, (1), 48-56, (2019) 